\title{
EVALUATION OF A LINEAR CUMULATIVE DAMAGE FAILURE MODEL FOR AN EPOXY ADHESIVE
}

\author{
David E. Richardson, Alicia Batista-Rodriguez, David Macon, and Peter Totman \\ Thiokol Corporation of Cordant Technologies Inc., Brigham City. UT 84302-0707
}

\begin{abstract}
Recently a significant amount of work has been conducted to provide more complex and accurate material models for use in the evaluation of adhesive bondlines. Some of this has been prompted by recent studies into the effects of residual stresses on the integrity of bondlines. Several techniques have been developed for the analysis of bondline residual stresses. Key to these analyses is the criterion that is used for predicting failure. Residual stress loading of an adhesive bondline can occur over the life of the component. For many bonded systems, this can be several years. It is impractical to directly characterize failure of adhesive bondlines under a constant load for several years. Therefore, alternative approaches for predictions of bondline failures are required. In the past, cumulative damage failure models have been developed. These models have ranged from very simple to very complex. This paper documents the generation and evaluation of some of the most simple linear damage accumulation tensile failure models for an epoxy adhesive. This paper shows how several variations on the failure model were generated and presents an evaluation of the accuracy of these failure models in predicting creep failure of the adhesive. The paper shows that a simple failure model can be generated from short-term failure data for accurate predictions of long-term adhesive performance.
\end{abstract}

\section{INTRODUCTION}

Recently a significant amount of work has been conducted to better characterize the material properties of adhesives. The programs that are conducting these studies recognize the need for more complex and accurate material properties for use in predicting the structural integrity of several critical bonded systems. For many adhesives, both the constitutive and failure properties are very much time and temperature dependent. ${ }^{1.23}$ Simple linear constitutive models and single valued failure models are not appropriate for all applications. For example, evaluations of bondline residual stresses can be complex. Several techniques have been developed for the analysis of bondline residual stresses. ${ }^{4.5,6.7}$ An essential element to these analyses is the criterion that is used for predicting failure. Residual stress loading of an adhesive bondline may not be short lived, but can be applied over the life of the component. For many bonded systems, this can be several years even when accounting for stress relaxation. It is impractical to directly characterize failure of adhesive bondlines under a constant load for several years. Testing would be costly and accurate controls would be difficult. Therefore, alternative approaches for long term loading failure predictions are required. In the past, cumulative damage failure models have been developed for other materials. These models have ranged from very simple to very complex. This paper documents the generation and evaluation of a couple of the most simple linear damage accumulation tensile failure models ${ }^{8.9}$ for an epoxy adhesive for use in any structural evaluation. The intent of the paper is to show how these failure models are generated and to study their accuracy in predicting creep failure of the adhesive.

It should be noted that due to technical information disclosure restrictions, all test parameters and results will be normalized. This will allow for an understanding of the intent of the paper without providing restricted data.

\section{TESTING}

The failure model that will be discussed in the paper was generated from constant load rate tests that were conducted using tensile adhesion buttons (see Figure 1) bonded with an epoxy. This specimen geometry was chosen for its size, ease of manufacture and ease of test. Table I shows the test matrix of loads and temperatures used to obtain data for the simple failure model. Seven tests were conducted per condition.

Copyright 2001 by Thiokol Corporation a Division of Cordant Technologies. All rights reserved. Published by the American Institute of Aeronautics and Astronautics, Inc. with permission. 


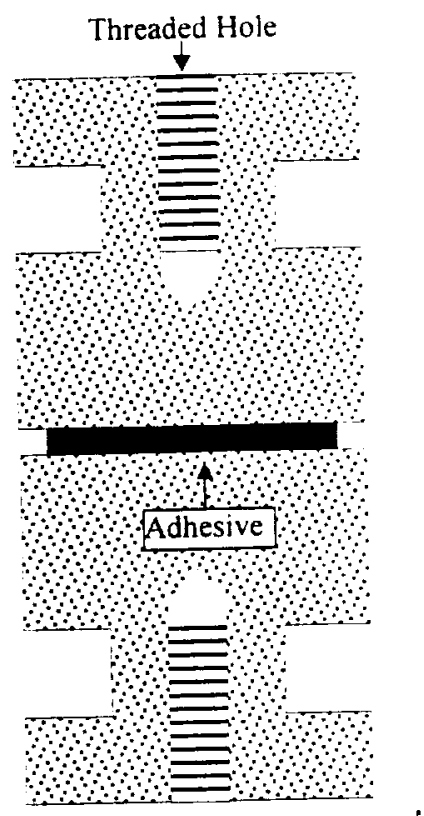

Figure 1: Tensile Adhesion Button Geometry

Table I: Test Matrix - Model Generation

\begin{tabular}{|l|c|c|c|c|}
\hline Temp. & $\begin{array}{c}\text { Base } \\
\text { Rate }\end{array}$ & $\begin{array}{c}10 \% \\
\text { Base } \\
\text { Rate }\end{array}$ & $\begin{array}{c}1 \% \\
\text { Base } \\
\text { Rate }\end{array}$ & $\begin{array}{c}0.33 \% \\
\text { Base } \\
\text { Rate }\end{array}$ \\
\hline Base & 7 & 7 & 7 & 7 \\
\hline Base $+10^{\circ} \mathrm{C}$ & 7 & 7 & 7 & 7 \\
\hline Base $+18^{\circ} \mathrm{C}$ & 7 & 7 & 7 & 7 \\
\hline Base $+24^{\circ} \mathrm{C}$ & 7 & 7 & 7 & 7 \\
\hline
\end{tabular}

As can be seen in Table I, each of the four load rates differed by approximately an order of magnitude. The range in temperature is small, but significant given the operating range of the adhesive. Because of the different loading conditions, the test sample failure times ranged from approximately five minutes (for the base rate) to approximately four days (for the $0.33 \%$ base rate).

For evaluation of the failure model, test specimens of the same geometry (Figure 1) were tested under constant load (creep). As with the constant load rate testing, seven tests were conducted for each condition. Table II shows the loading conditions and the temperatures tested in this creep configuration. The chosen applied creep loads decrease for each temperature condition because the strength of the adhesive decreases with increasing temperature. The load values were chosen based on limited constant load and constant load rate testing that was conducted prior to this creep testing. Preliminary estimates of the failure models described in the next section were used to develop these load conditions.
Table II: Test Matrix - Model Verification

\begin{tabular}{|l|c|c|c|c|c|c|}
\hline Temp. & $\begin{array}{c}\text { Load } \\
\# 1\end{array}$ & $\begin{array}{c}\text { Load } \\
\# 2\end{array}$ & $\begin{array}{c}\text { Load } \\
\# 3\end{array}$ & $\begin{array}{c}\text { Load } \\
\# 4\end{array}$ & $\begin{array}{c}\text { Load } \\
\# 5\end{array}$ & $\begin{array}{c}\text { Load } \\
\# 6\end{array}$ \\
\hline Base & $100 \%$ & $94 \%$ & $90 \%$ & $86 \%$ & & \\
\hline$+10^{\circ} \mathrm{C}$ & $83 \%$ & $79 \%$ & $74 \%$ & $70 \%$ & $65 \%$ & $61 \%$ \\
\hline$+18^{\circ} \mathrm{C}$ & $53 \%$ & $50 \%$ & $47 \%$ & $44 \%$ & & \\
\hline$+24^{\circ} \mathrm{C}$ & $43 \%$ & $40 \%$ & $37 \%$ & $36 \%$ & & \\
\hline
\end{tabular}

\section{FAILURE MODELS}

In the following paragraphs, the first objective of this paper will be addressed. The basic failure theory will be discussed, and several minor variations to the theory will be presented to account for temperature effects.

\section{FAILURE THEORY}

The base failure theory that will be used in this paper is similar to that documented in reference 8 , and is based on the theory of linear cumulative damage? The following is the basic equation:

$$
N_{\beta}=\left[\int_{0}^{1} \sigma^{\beta} d t\right]^{\frac{1}{\beta}}
$$

For constant load rate conditions this reduces to:

$$
t_{f}=(1+\beta)\left(\frac{N_{\beta}}{\sigma_{f}}\right)^{\beta} \quad \text { where } \quad \sigma_{f}=\text { st }_{f}
$$

For constant load conditions the equation reduces to:

$$
t_{f}=\left(\frac{N_{\beta}}{\sigma_{f}}\right)^{\beta}
$$

Where:

$$
\begin{aligned}
& \mathrm{s}=\text { stress rate } \\
& \sigma_{\mathrm{f}}=\text { Failure Stress } \\
& t_{f}=\text { Failure Time } \\
& N_{\beta}=\text { Norm (a failure property of the material) } \\
& \beta=\text { Beta (a failure property of the material) }
\end{aligned}
$$

Equations (1-3) imply that the failure data from constant load rate tests can be used to predict failure in constant load conditions. If extrapolation is assumed to be accurate, constant load rate tests that take minutes or days can be used to predict failure in constant load conditions for several years. This assumption has been used several times in the past. As stated above, this paper evaluates the accuracy of these equations and this extrapolation assumption. 


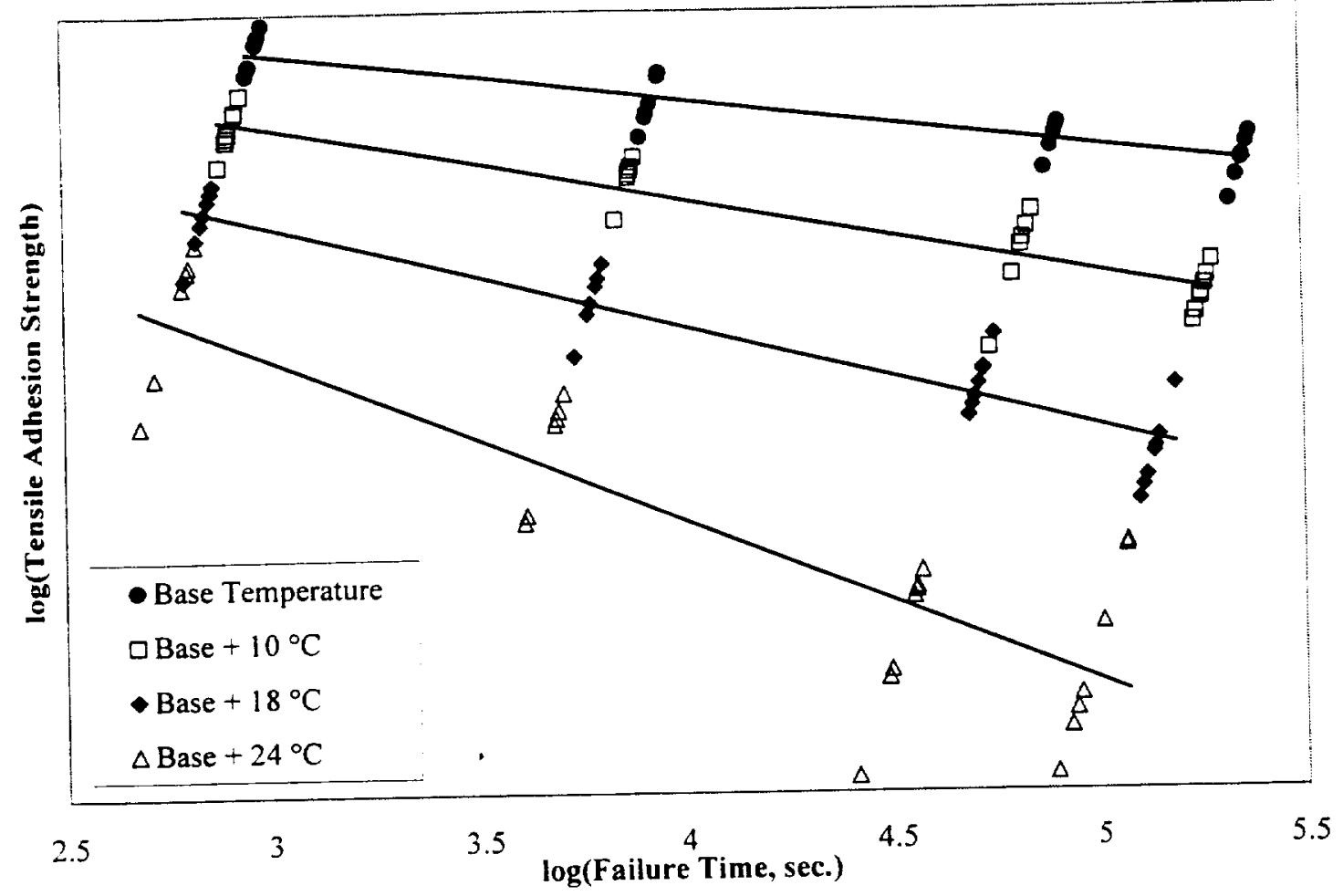

Figure 2: Constant Load Rate Failure Data and Individual Failure Criteria

Note that the theory as stated does not address the effects of temperature. Several variations on the theory will be discussed which account for temperature changes. The accuracy of each will be evaluated for use with this epoxy adhesive.

\section{INDIVIDUAL FAILURE CRITERIA}

A plot of the constant load rate failure data in $\log -\log$ space can be seen in Figure 2. For each temperature condition, a separate curve fit of the form shown in equation (2) was generated and plotted in Figure 2. As can be noted in the figure, there is a significant amount of scatter in the failure data. This scatter will be addressed in subsequent sections of this paper. The failure parameters for these curve fits can be found in Table III. The $\mathrm{N}_{\beta}$ 's are normalized to the average. It is interesting to note that these $N_{\beta}$ 's are nearly constant with temperature. The $\beta$ 's vary with temperature.

Table III: Failure Parameters by Temperature

\begin{tabular}{|l|c|c|}
\hline Temperature & $\mathrm{N}_{\beta}$ (normalized) & $\beta$ \\
\hline Base Temp. & 1.03 & 26.8 \\
\hline Base $+10^{\circ} \mathrm{C}$ & 0.99 & 17.5 \\
\hline Base $+18^{\circ} \mathrm{C}$ & 0.93 & 12.8 \\
\hline Base $+24^{\circ} \mathrm{C}$ & 1.07 & 7.3 \\
\hline
\end{tabular}

\section{BETA SHIFT FUNCTION}

The $\beta$ values seen in Table III vary linearly with temperature as shown in Figure 3.

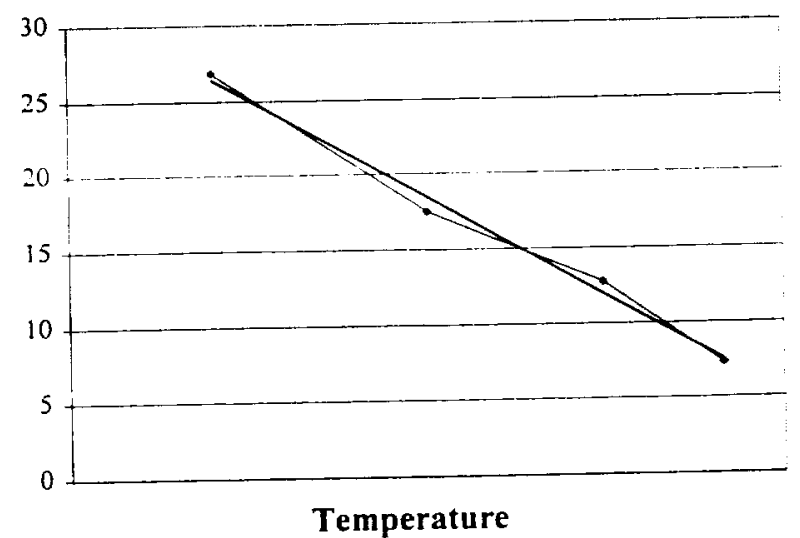

Figure 3: $\beta$ as a Function of Temperature

Using this relationship, the four separate failure criteria (for the different temperatures) of the previous section can be consolidated into one single failure model. This failure model is created using equation (2) with $N_{\beta}$ being the average of those from the previous section, and a linear equation being substituted for $\beta$. $\beta$ being a function of temperature as seen in Figure 3 . 


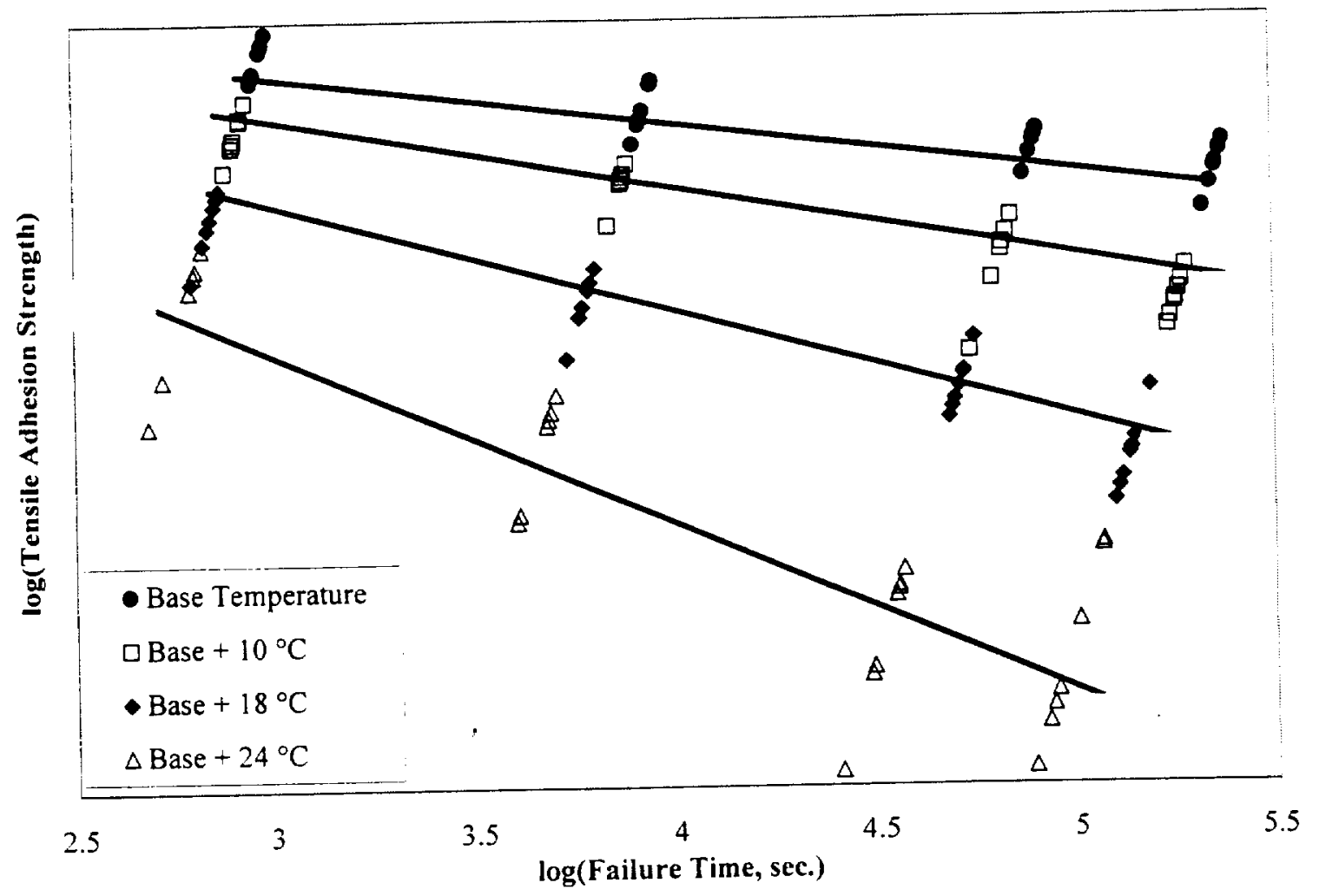

Figure 4: Constant Load Rate Failure Data and Failure Criterion With a Beta Shift Function

Figure 4 shows the constant load rate failure data and failure model with a variable $\beta$. Not surprising, the predicted failure is nearly equivalent to that seen in Figure 2. The advantage of this approach is the use of a single equation for the temperature conditions of interest.

There is a lot of scatter in the test data. which is inherent in long term tests (some of these tests took over four days of loading before failure occurred). The coefficient of variation of the test data from the prediction was determined to be approximately $15 \%$.

\section{TIME/TEMPERATURE SHIFT FACTOR}

An alternative approach for addressing the temperature issue is through time/temperature shift factors similar to that done in viscoelasticity ${ }^{3}$. Figure 5 shows the constant load rate failure data with the higher temperature data shifted to obtain a final master failure curve. The shifting was done visually to provide the smoothest transition from one temperature to another. Linear curve fits of each set of data are provided for reference, and were used as an aid in shifting the failure data.
Note that the failure data do not fall in a straight line. An equation of the form noted in equation (2) could not be used to fit the failure data with much accuracy. A higher order equation would be required to fit the failure data. The intent of this study was to focus on evaluating the accuracy of this simple linear cumulative damage failure model. not to extend the theory. Therefore, this approach for modeling the failure in the epoxy adhesive of interest was not pursued to any greater extent. These data are provided to show that this approach cannot be used, but there may be opportunity for future investigations into higher order theories.

\section{VERIFICATION OF THE FAILURE CRITERIA}

The second objective this paper was to evaluate the accuracy of the failure model in predicting creep-type failure. The intent was to evaluate model with tests that have everything equivalent but the load history. Therefore, this testing was conducted using the same type of specimen (see Figure 1). The samples were put in a creep stand and subjected to a constant load until failure occurred. As was seen in the test matrices, even equivalent temperatures were employed. 


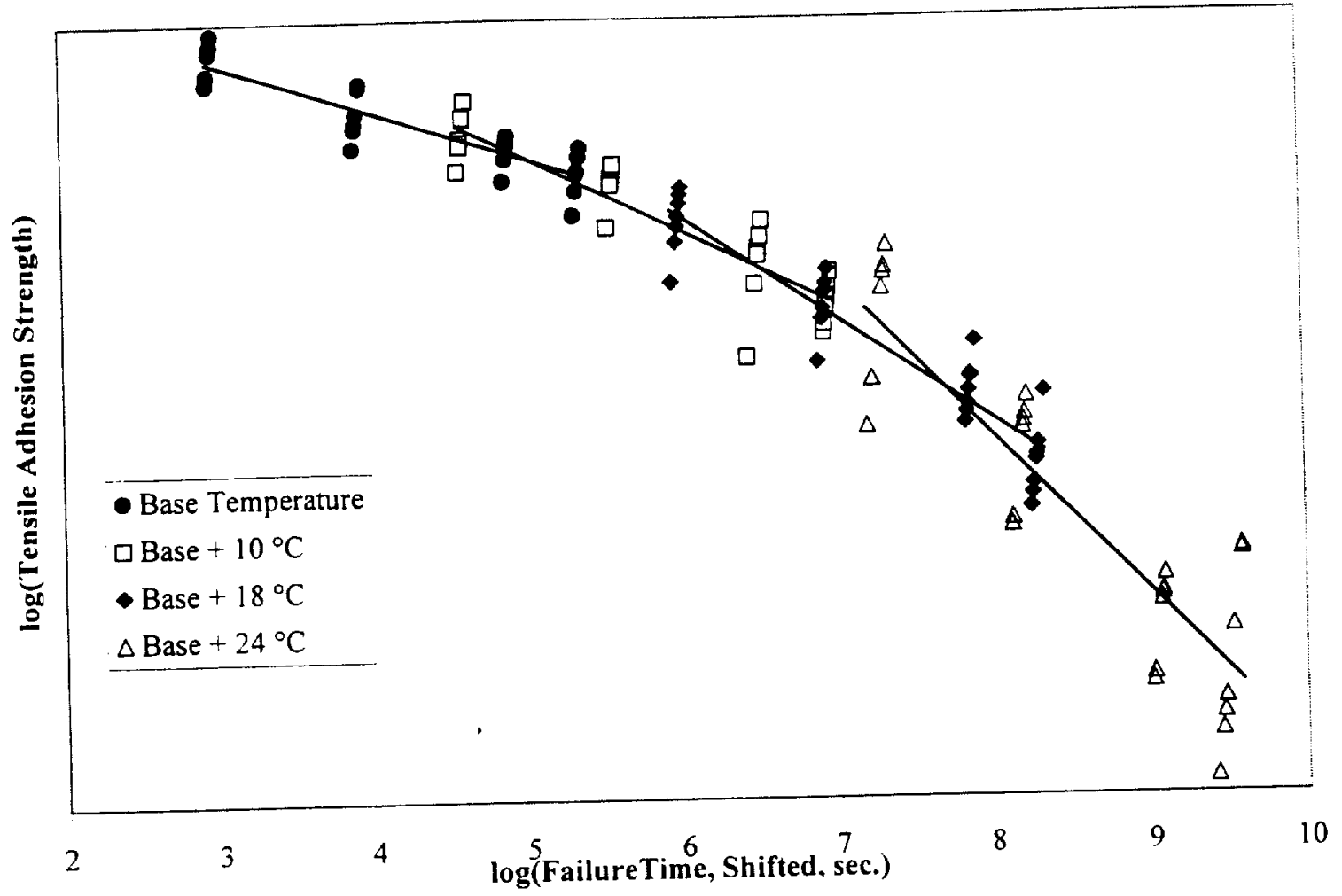

Figure 5: Constant Load Rate Data Shifted With a Time/Temperature Shift

The constant load (creep) failure data and the model prediction using equation (3) with the $\beta$ being a linear function of temperature can be seen in Figures 6-9. Included in the figures is a statistical lower bound prediction for the strength of the adhesive. The lower bound is three coefficients of variation away from the predictions (similar to a lower three standard deviation estimate). It should be noted, that the coordinates of the vertical axis in each of these plots (though not shown) are equivalent so that comparisons can be made between the figures.

As can be seen in Figures 6-9, the prediction of failure of the creep loading is good for all temperature conditions. Similar to the constant load rate tests. there is a lot of scatter in the test data. The figures also show that the statistical lower bound estimate of the failure is conservative and brackets all of the test data. It should be noticed that when predicting time-to-failure, there is a dramatic difference between the predictions of actual failure and the statistically penalized predictions of failure. The predicted times-to-failure can differ by orders of magnitude. When predicting factors of safety using the failure model described herein, a statistically penalized failure model should be used to ensure conservatism in the prediction. The use of a statistically penalized failure model may lead to excessive conservatism, and care should be taken to choose the proper magnitude of penalties to impose.

It should be noted that the failure data used to generate the failure model, had times-to-failure ranging from five minutes to approximately four days. These data were used to accurately predict failure out to approximately 140 days. The testing indicates that accurate predictions can be made even with the significant extrapolation. As mentioned above, extrapolations out to longer times may be required for some programs. It is felt that this testing indicates that a good estimate of failure at these times can be made.

\section{CONCLUSIONS}

Constant load rate testing of tensile adhesion buttons was conducted to generate data for the development of a simple linear cumulative damage failure criterion. Several approaches for modeling failure as a function of temperature were evaluated. Modeling of the failure using a $\beta$ failure parameter that is a linear function of temperature was found to be most accurate. The use of time/temperature shift factors for this simple failure model was not found to be appropriate. 


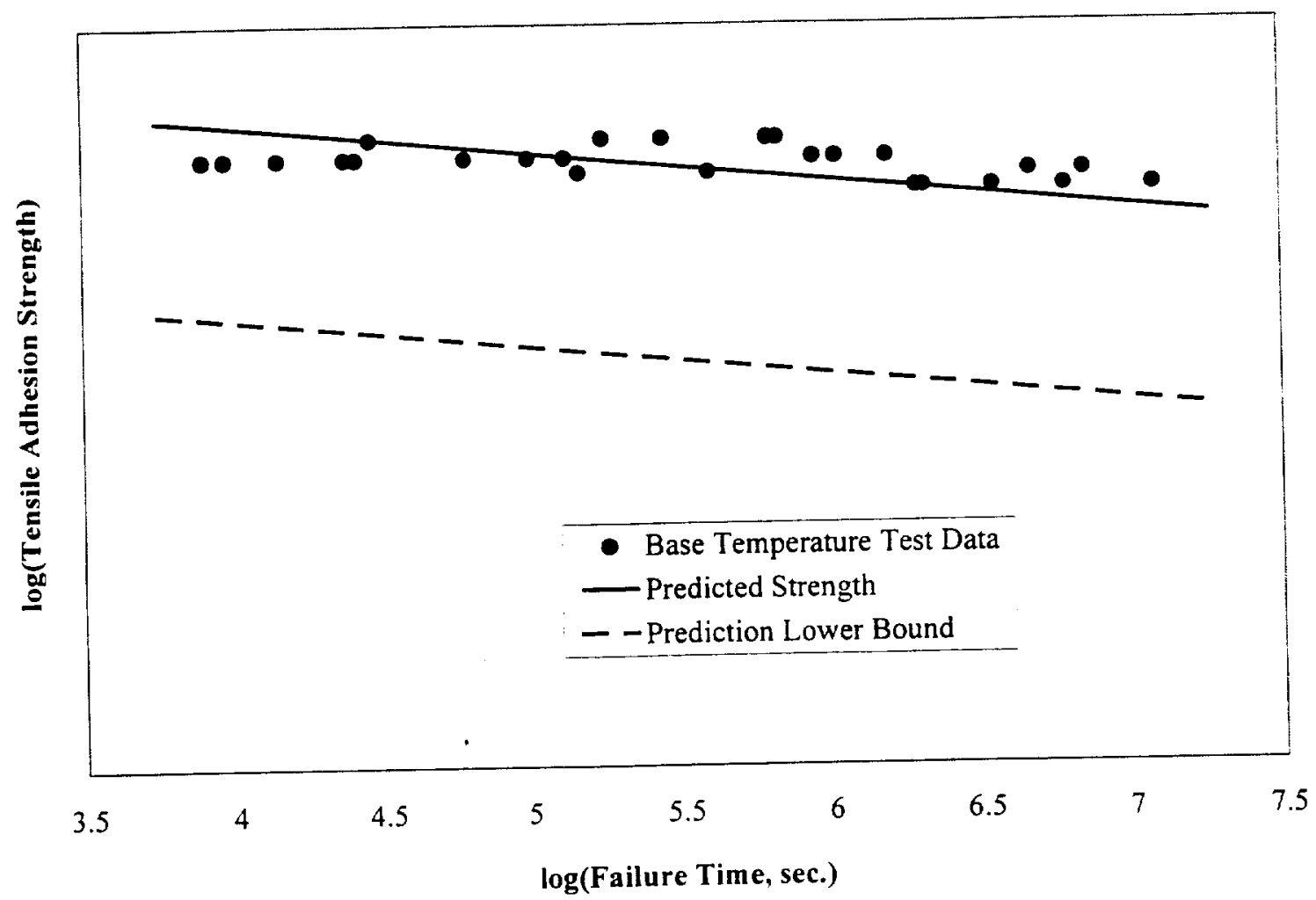

Figure 6: Creep Failure Data vs. Prediction for the Base Temperature

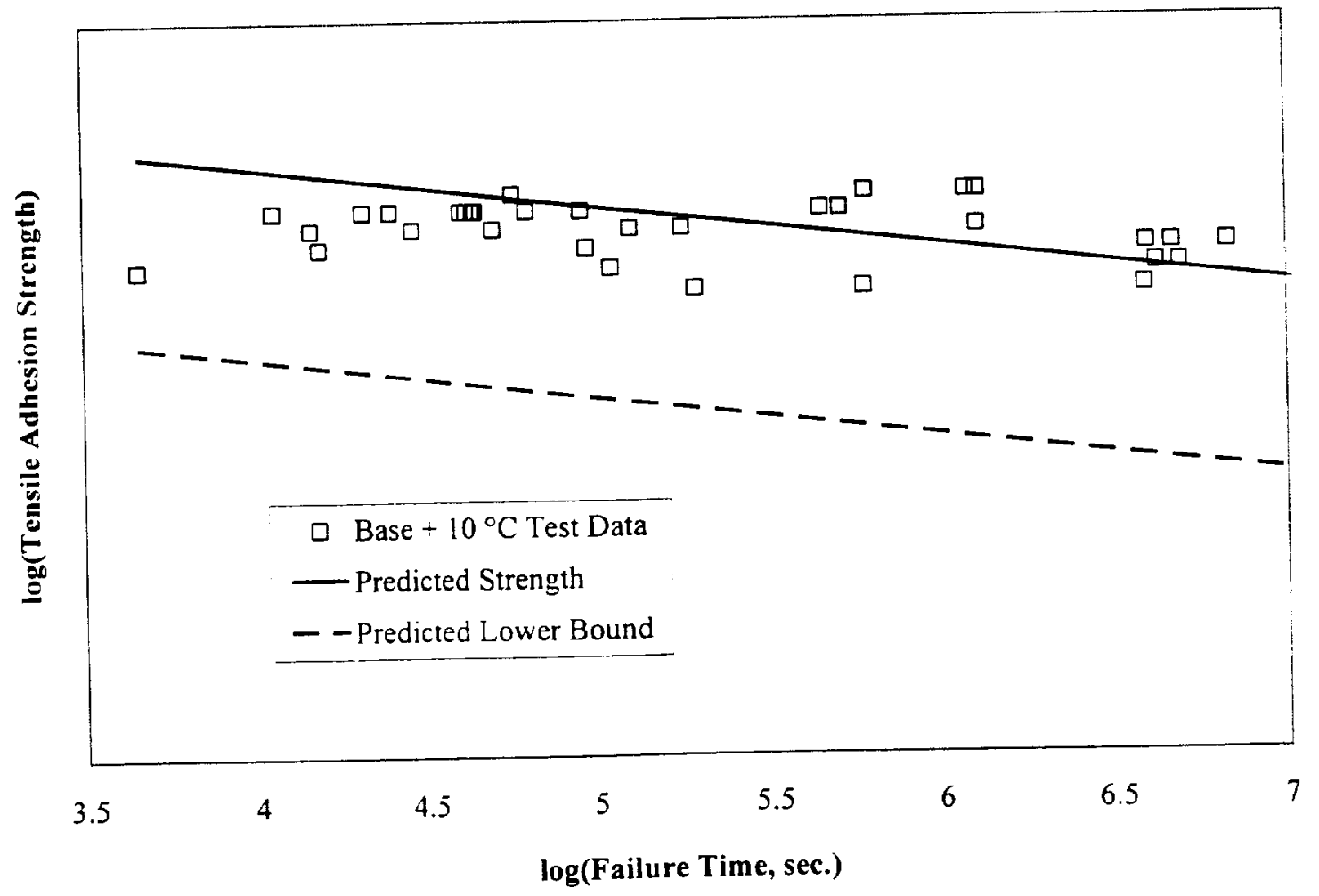

Figure 7: Creep Failure Data vs. Prediction for the Base Temperature $+10^{\circ} \mathrm{C}$ 


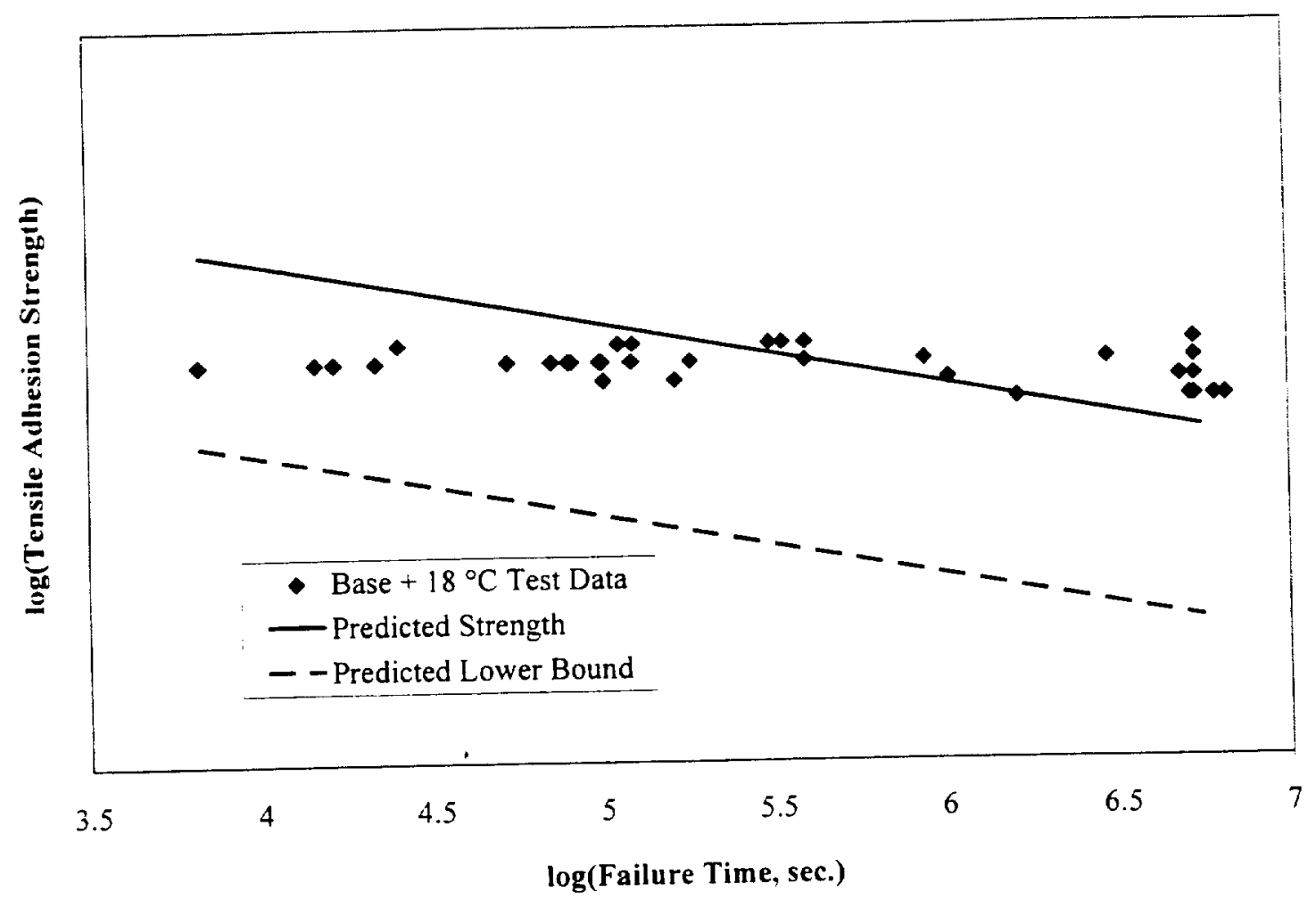

Figure 8: Creep Failure Data vs. Prediction for the Base Temperature $+18^{\circ} \mathrm{C}$

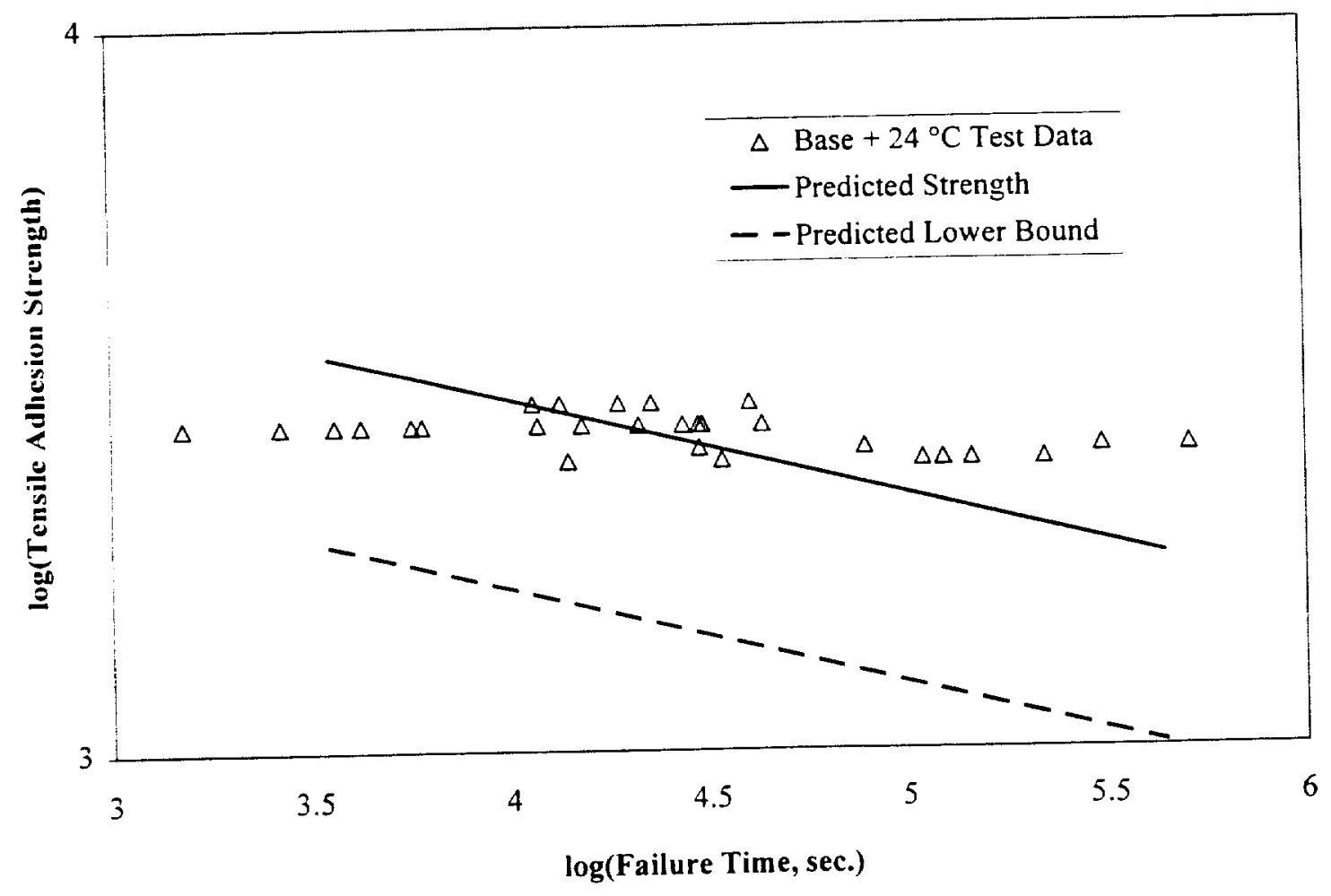

Figure 9: Creep Failure Data vs. Prediction for the Base Temperature $+24^{\circ} \mathrm{C}$ 
Constant load (creep) testing with the same tensile adhesion buttons was conducted to evaluate the accuracy of the simple failure model. A good correlation was shown between the test data and the predictions from the failure model. The testing indicates that short-term test data can be used to accurately predict long-term failures.

All the testing indicates that there is significant scatter in the failure data for long for long-term tests. This scatter should be taken into account for when evaluating factors of safety.

\section{REFERENCES}

D. E. Richardson, R. A. Crook, "Notes on Constitutive Property Changes Due to Nonlinearities and Post Cure Aging for EA946 Adhesive," JANNAF Interagency . Propulsion Committee, Rocket Nozzle Technology SubCommittee, Albuquerque NM, Dec. 9-13, 1996.

2 R. A. Crook and D. E. Richardson, "Time Dependence of a Structural Adhesive Bondline," $17^{\text {th }}$ Annual Meeting of the Adhesion Society, Orlando FL, Feb. 19-24, 1994.

3 D. Gutierrez-Lemini, "Failure Properties of EA913NA and EA946 Bonds Final Test Report," TWR-66335, Thiokol Corporation, May 27, 1997.

4

D. E. Richardson, R. A. Crook, B. E. Phipps, "Analyses of Manufacturing Residual Stresses in the Shuttle Redesigned Solid Rocket Motor Nozzle," JANNAF Interagency Propulsion Committee, Rocket Nozzle Technology SubCommittee, Huntsville, AL, Oct. 19-21, 1993.

5 D. E. Richardson, "Bondline Residual Stress Analysis," $35^{\text {th }}$ Aerospace Sciences Meeting and Exhibit, Lecture Series - Mathematical Models and Computational Methods for Solid Rocket Motors II, Reno, NV, Jan. 6-9, 1997.

6 C. M. Ehle, "Finite Element Modeling of an RSRM Nozzle Bonding Process," ABAQUS Users' Conference, Newport, RI, May 1998.

7 C. M. Ehle, "Finite Element Analysis of an RSRM Nozzle Bonding Process," JANNAF Interagency Propulsion Committee, Rocket Nozzle Technology Sub-Committee, Salt Lake City, UT, March 16-20, 1998.
8 K. L. Laheru, "Development of a Generalized Failure Criterion for Viscoelastic Materials," Journal of Propulsion and Power, Vol. 8, No. 4, July-Aug. 1992.

9 M. A. Miner, "Cumulative Damage in Fatigue," Journal of Applied Mechanics, Vol. 12, Sept. 1945. 